\title{
Informal learning recognition through a cloud ecosystem
}

\author{
Francisco José García-Peñalvo, Mark Johnson, Gustavo Ribeiro Alves, \\ Miroslav Minović, Miguel Ángel Conde-González
}

\begin{abstract}
Learning and teaching processes, like all human activities, can be mediated through the use of tools. In- formation and communication technologies are now widespread within education. Their use in the daily life of teachers and learners affords engagement with educational activities at any place and time and not necessarily linked to an institution or a certificate. In the absence of formal certification, learning under these circumstances is known as informal learning. Despite the lack of certification, learning with tech- nology in this way presents opportunities to gather information about and present new ways of exploit-ing an individual's learning. Cloud technologies provide ways to achieve this through new architectures, methodologies, and workflows that facilitate semantic tagging, recognition, and acknowledgment of in- formal learning activities. The transparency and accessibility of cloud services mean that institutions and learners can exploit existing knowledge to their mutual benefit. The TRAILER project facilitates this aim by providing a technological framework using cloud services, a workflow, and a methodology. The services facilitate the exchange of information and knowledge associated with informal learning activities ranging from the use of social software through widgets, computer gaming, and remote laboratory experiments. Data from these activities are shared among institutions, learners, and workers. The project demonstrates the possibility of gathering information related to informal learning activities independently of the con-text or tools used to carry them out.
\end{abstract}

\section{Keywords:}

Informal learning recognition, Cloud-based information systems, Competence, Integration, TRAILER

\section{Introduction}

The emergence of information and communication technology (ICT) and its application in different contexts has entailed a revolution in the way communication tools are used by people in their daily life. Computers, the Internet, mobile devices, and Web 2.0 tools provide new ways to access, share, and exchange information and knowledge. As part of this process, learners and teachers have embraced new technologies as a means of acquiring tools and resources for learning [1] and engaging with each other through the use of social networks. Teaching practices have consequently adapted to changes in the technological environment [2].

However, new organisational challenges arise from the new technology. These include:

(1) The problem of technology deviation [3], whereby the need to continuously upgrade technologies confines learners and teachers to technical processes, rules, and resource constraints so that technological concerns rather than pedagogical requirements take precedence.

(2) The problem of interoperability [4], exemplified by the fact that the most representative ICT tool applied in a learning context, the learning management system (LMS), has limited synergistic capabilities. Lack of reusability and portability can 

lead to lock-in with system vendors and a lack of flexibility for learners, and presents barriers for the integration of new tools or the evolution of existing systems.

(3) The problem of centralisation, whereby institutional requirements shape the technology and not learner requirements. Rather than bringing their own favoured tools to their learning, learners are forced to use institutional tools with functionality that often reproduces that of extra-institutional tools, which are invariably more effective than the institutional variety $[5,6]$.

(4) The problem of access beyond the institution, where the LMS is often unavailable to learners once they finish their studies, so that integration of lifelong learning and institutional learning is difficult $[7,8]$.

Cloud computing, defined as "a model for enabling convenient, on-demand network access to a shared pool of configurable computing resources (e.g. network, servers, storage, applications, and services) that can be rapidly provisioned and released with minimal management effort or service provider interaction" [9], is one of the major drivers of change in education. Broadly, this technology marks a transition from local computing offerings to external ones [10]. Offerings can be fairly simple, ranging from services, such as a virtualised desktop, data storage, and email, to whole applications such as an office application suite, a security package, and collaboration tools [11].

Cloud computing applied to learning and teaching processes is known as cloud learning. The concept is built on three service models: infrastructure as a service (laaS); platform as a service (PaaS); and software as a service (SaaS). It can be understood as a shared pool of learning courses and digital assets and resources that instructors and learners can access via computers, laptops, IPTVs, mobile phones, and other portable devices [12]. The technical capabilities of cloud learning invite new pedagogical designs that emphasise learner-centred resource-sharing and collaboration among learners to jointly build personalised learning environments [3].

The flexibility of cloud technology can help learners to bring technologies of their choice to their learning rather than having institutional technology imposed on them. In this way, some of the issues identified for the technological deviation problem might be addressed, with greater personalisation facilitating more attention to higher-level thinking skills and group intelligence rather than technical coordination. At the same time, problems of interoperability, integration, and reuse can be overcome by increased use of web services on cloud platforms.

In considering the third problem of institutional-centred platforms, integration with personal cloud-based technologies is becoming a technical architecture requirement as institutions seek to integrate their own services with Web 2.0 tools under the student's control [13]. The rationale for the shift in this locus of control is that personalisation can improve learning by empowering students to manage their learning at their own pace [14] and with their own technology within the context of activities of their daily lives that are managed using the same technologies. This can be achieved through the broad concept of a personal learning environment (PLE), which directly addresses the technical coordination problems of learners by providing a means to coordinate services from the institution with other services from the web [15].

The PLE approach facilitates coordination of institutional learning episodes and real life. Informal learning is an important element in the support of lifelong learning. A technical means for coordination of informal learning brings the potential for recognition and exploitation of informal learning activities. In the workplace, informal learning is important because it can enhance employability and produce positive benefits for managers and companies. Recognition of informal learning produces information that can be used to develop knowledge of skills and know-how within an organisation and be an indicator of social norms and preferred patterns of behaviour $[16,17]$. For employees, recognition of informal learning provides an opportunity to keep their skills up to date, and such recognition can become part of the workplace culture for self-development beyond corporate training regimes. These opportunities have led to interest in informal learning from the corporate world, driven by a desire to capitalise on the intellectual assets of the workforce, to manage organisational knowledge, and to recognise that informal learning may prove a cost-effective way of developing competence [14] driven by the increasing transparency of technology [18].

The TRAILER (Tagging, Recognition, Acknowledgement of Informal Learning Experiences) project $[19,20]$ describes an architecture and methodology that facilitate the exchange of experiences among employees or students and institutions. The aim is to expose competencies that are acquired informally that would otherwise be invisible to the institution. The methodology is supported by a cloud-based architecture that combines different tools for semantic tagging of learning activities carried out in different contexts, such as web-browser applications, remote laboratories, games, and social software widgets. TRAILER does not just define a cloud-based system that integrates resources [21], facilitates a set of specific services (such as mobile services) [22] and teaching [23], and defines a cloud learning management system [24] or PLE [25]. It also facilitates exchange of knowledge related to informal learning activities among learners and institutions. In this paper we focus specially on how different types of activity (activities carried out through a browser, game, or widget, or in a remote laboratory) are integrated in the architecture, tagged by the user, and published for institutions, employers, and other individuals.

The remainder of the paper is organised as follows. Section 2 describes the TRAILER project and its architecture. Then three informal activities for which information is gathered by the system are described: games (Section 3); remote laboratories (Section 4), and social software widgets (Section 5). Section 6 discusses some evaluation results for the system.

\section{TRAILER project}

TRAILER [19] is a research project funded by the European Union through the Lifelong Learning Programme. The project is based on the premise that although technology may afford practical solutions to problems of personal learning, technological approaches can present new issues of ownership and control. Adesirable aim is that learning processes are under the control of the learner, which requires integration of informal learning with formal approaches balancing personal enquiry and coordination with the need for institutional accreditation of evidence of competency.

The project achieves this balance by bridging the learner's activity with institutional processes. The learner identifies episodes and evidence of informal learning in any of the different spaces in which she learns (formally or informally). She submits links to these or uploads them to the TRAILER tool located within her portfolio, and then tags them in relation to a predefined but evolving competence catalogue. The tool is linked to the institutional interface in such a way that relevant experiences are accessible to the institution. Other experiences that may be personally relevant to the learner are accessible to her alone.

In this way, informal learning experiences become transparent and useful both for the individual, who can monitor and justify to others the development of her competencies, and for the institution, which can follow the progress of individual and group competencies and identify emerging new competencies.

The technical architecture and methodology of TRAILER facilitate co-creation of a portfolio of informal learning activities and 


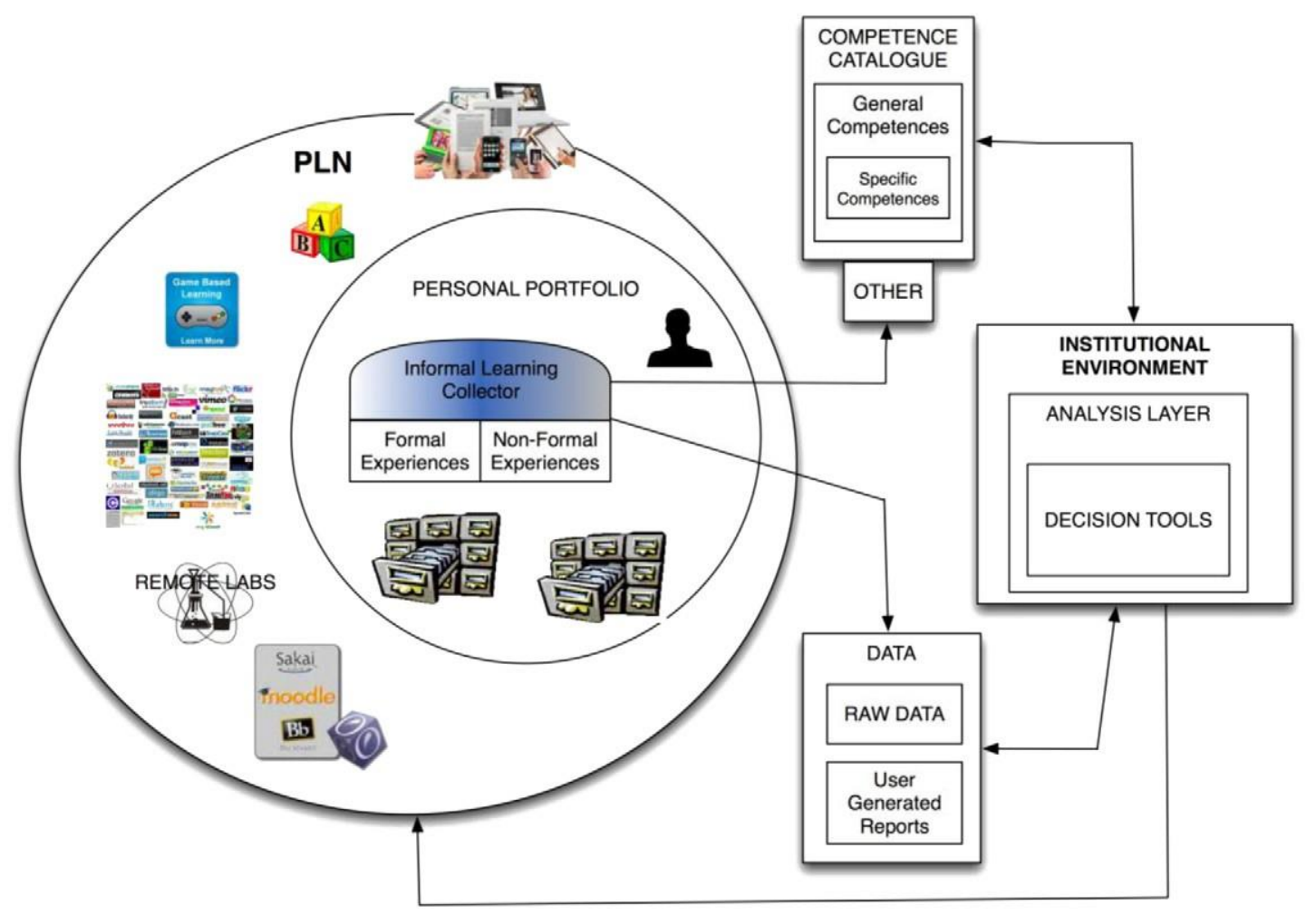

Fig. 1. Technological framework that supports the TRAILER methodology. This includes a cloud personal learning network (on the left-hand side), which integrates a portfolio system and institutional tools (on the right-hand side) such as an institutional environment, a repository, and a competence catalogue.

a discussion that helps both learners and institutions to integrate informal learning in preparation for sharing or formal accreditation [26]. The architecture comprises a cloud-based framework with several components and interfaces for the interaction required. The interfaces are based on the use of web services that connect components developed in different programming languages in a transparent way. The framework is described in Fig. 1.

It consists of:

- A personal learning network (PLN), which includes different learning tools that the learner can use in an informal way. To implement the system and gather information on informal learning activities, several types of tool-mediated activity are considered: informal activities carried out through a browser (e.g. the use of online tools, forums, and remote laboratories in informal contexts, searches for resources in repositories), with a widget container (that could combine different tools including social software), or playing games through a mobile device browser. With this architecture, other possible informal activities could additionally be included, particularly other web-based activities.

- A portfolio system in which informal, non-formal, and formal learning experiences can be stored and published. The TRAILER portfolio has an interface to facilitate the gathering of informal learning activities. This is called the informal learning collector (ILC). This interface can be used to gather informal learning activities carried out with different tools.

- There are several institutional tools. The competence catalogue is used to categorise informal learning experiences while taking into account learner or institutional perspectives. The institutional environment allows analysis of published information to support dialogue with the learner and to facilitate decisionmaking concerning learning issues within the institution (e.g. accreditation processes). The repository stores information to be analysed and can generate reports that could be useful to both the institution andlearners.
The competence catalogue facilitates semantic description of informal learning experiences. It includes some competences at a general level that are in any institutional catalogue, competences related specifically to the institution, and other competences provided by the users. Each competence level can feed the others. For example, if a competence at the institutional level appears in several institutions and several times, it can be incorporated at the general level. A similar process applies to the individual competences of students. The competence catalogue also links competences to a reference framework for which the project collaborates with others such as INLOC (http://wiki.teria.no/ display/inloc/Home). The competence catalogue operates as a web service that is used by the other components of the TRAILER architecture. It facilitates the association of information to an informal activity that can then be exploited in a semantic way.

With this framework it is possible to define a workflow that makes informal learning experiences transparent to learners and institutions in such a way that both can benefit. The workflow is as follows. (1) The learner, after identifying an instance of informal learning that has taken place in her PLN, tags it using the ILC interface with tags from a predefined competence catalogue. This information is then stored in the learner's portfolio. (2) The learner later reviews the range of tagged informal learning instances and decides which of them she will make visible to an institution (her employer or tutors). (3) The institution can view this information and analyse it. (4) The information permits a dialogue with the learner to agree on competences acquired through informal processes and to orient future activity. The information also allows the institution to plan formal and non-formal actions in light of the informal learning that is taking place, and to match learners to others with similar interests according to their informal learning activity, interests, and development.

In this paper we focus on why some non-common informal learning activities are considered in the project (games, remote laboratories, and widgets), how they are integrated in the 
framework, and how they facilitate tagging of informal learning experiences.

\section{Special tools on the cloud to gather informal learning activities}

The TRAILER project facilitates the use of contrasting tools to gather informal learning activities. The most common tool is a web browser. Navigation to a web page, participation in a forum, reading of a blog, and watching of a video constitute examples of activities that a learner might choose to submit. However, these are not the only ways to gather information. In this section we present other ways to take into account informal learning activities by using tools on the cloud.

\subsection{Games}

Games represent a new interactive medium that is different from TV, radio, and books. Research shows that the proportion of leisure time spent on playing games is overtaking that spent watching TV. Fun is often cited as a reason to play games [27]. The source of fun in different types of game can come from solving puzzles or demonstrating acquired skills as a response to a challenge that the game provides. If there is no challenge or if the challenge is insufficiently great, a game can be perceived as boring and is usually abandoned. Consequently, the main problem in constructing educational tools based on games is the question of finding a balance between entertainment and educational value [28].

Games as an interactive medium provide educators with possibilities to create learning contexts as simulations closely related to real life situations. The assumption is that effective simulations within a game context can be programmed in a manner whereby the inherent motivating factors from real life also apply to engagement with the game. This results in an authentic activity in which meaning and relevance naturally emerge [29].

Recent research indicates that games have positive effects on concentration, decision-making processes, problem-solving skills, logical thinking, creativity, teamwork, and computer skills [30]. According to Estalló, people who play games have more developed intellectual skills than those who do not [31].

There is evidence that the experience of fun is related to levels of dopamine [32]. On solving some problem or situation, neural activity appears to lead to higher dopamine levels. This presents some intriguing explanations for the motivation for problemsolving and biological survival mechanisms. It further suggests a positive correlation between learning and fun.

The mechanism described above only appears to work when the learner's tasks are suited to their immediate needs and context. Thus, a one-size-fits-all approach, which is usually taken into schools, cannot satisfy the learning needs of each student in a class. The emphasis in a PLE is on the contextual needs of learners and their coordination challenges. If flexibility and personalisation can be incorporated in a PLE, then it may be possible to enable learners to learn in ways they determine to be fun.

Educational games are thus an important part of any PLE as an informal learning tool and are included among the activities in the TRAILER project. The challenge is for a player to pursue enjoyable activities within a game without explicit acknowledgement of their learning; that learning is then retrospectively tagged and entered into their portfolio.

A software platform was developed to support the production of educational games by educators without any programming skills. The software separates the roles of game designer and knowledge expert so that participants in the game creation process perform only the activities within their own speciality. The system consists of three parts: a knowledge repository, a game editor
(Fig. 2), and a web-based game interpreter (Fig. 3). Learning objects stored in the data repository represent knowledge. The game editor is used to define the game world, rules, scenarios, and interactions between players and characters, and to incorporate knowledge into the game. The game interpreter presents the game to the user, creates the game interface, and monitors communication between the game and the user. The game editor creates a special XML file that contains definitions of the game and the knowledge. The $\mathrm{XML}$ file is then used by the game interpreter to create a game instance [33].

The software is written in Java. The game editor was developed as a stand-alone desktop application. The repository is a web application with web service interfaces and the game interpreter is a Java applet provided to end users via the Internet [33].

Tagging of informal learning occurs in a number of ways. For smaller games, informal activity data about the game played are sent to the ILC. Largergames can take hours or even days or months to complete, so tagging occurs after each game level or a few times per level as the player progress through the game.

An educator can offer tagging of informal learning at any stage of the game, depending on his estimation of the significance of each quest or step. The game editor is expanded to allow the educator to offer tagging at any time during the game (Fig. 1). Tagging can occur with or without player acknowledgement. This allows educators to automate the process of sending informal learning activities to the ILC.

The game developed for the TRAILER project has educational content related to computer networks and players have the option of sending learning activities to the ILC after each quest is completed (Fig. 3).

In the current version, an educator can only submit textual descriptions, which are sent together with the game URL to the ILC. In future developments, we plan to send a screenshot of the game state.

Communication with the ILC is realised via web services available through JSON-RPC calls. Since the game is executed as a Java applet, this communication requires integration of a Java library. The applet has to be signed with appropriate security configurations to allow connection across network domains.

To implement player authorisation for the ILC, the first step of the game was modified so that players are asked to provide their ILC username and password. The game applet is deployed on a separate server, but games can easily be added as a resource to any LMS such as Moodle.

\subsection{Remote $L A B s$}

Remotelaboratories are physicalspaces with realapparatusand instruments connected to the Internet. They allow both students and teachers to remotely conduct real experiments through a simple web browser. Aktan et al. first described the concept of remote experimentation in 1996 [34]. There is now a consensus that remote laboratories play a significant role in the acquisition of experimental skills if successfully combined with real hands-on laboratories and virtual laboratories [35-39]. The types of experimental skill that students can acquire in any type of laboratory havebeenclarified byFeiselandRosa[40]. Theseauthorsdescribed 13 fundamental objectives for engineering instructional laboratories that serve as a guide when considering the types of skill that can be acquired from a particular experiment in a real, virtual, or remote laboratory. In the case of a remote experiment, if the provider can clearly identify the learning outcomes and the skill gained, then a student who successfully completes the experiment can acknowledge having acquired the associated skill.

Thus, after completing a remote experiment available in the web, individuals can tag an informal learning activity and associate 


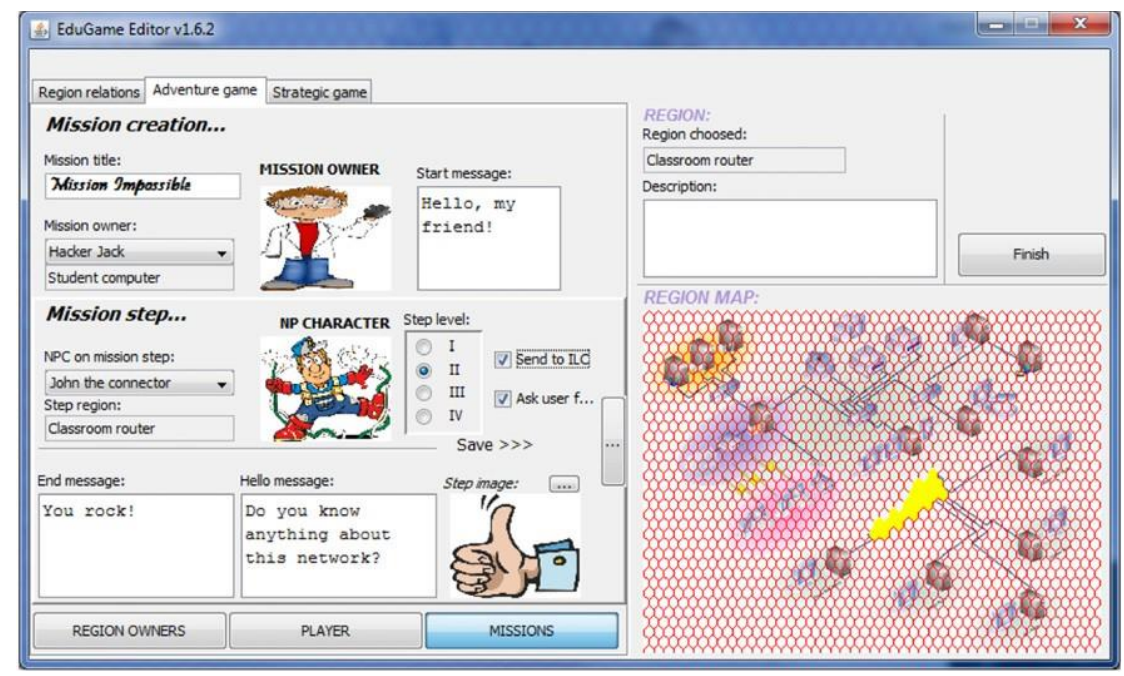

Fig. 2. Educational game: game editor.
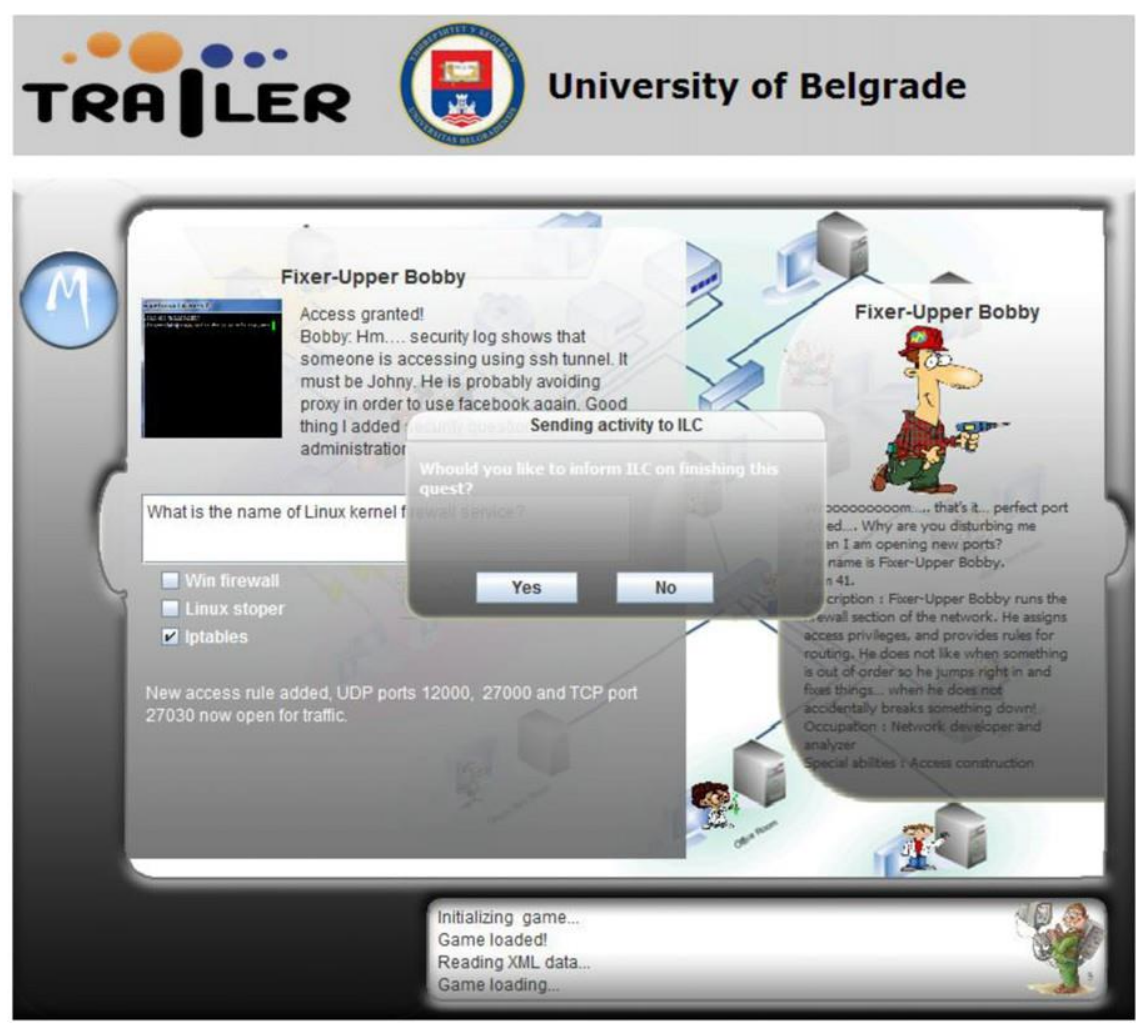

Fig. 3. Educational game: computer networks.

it with a skill gained. The question remains as to how to tag thatactivity and provide evidence of actually having done it. Remote laboratories fit into the TRAILER project as a source of learning activities and competence gained in the area of science, technology, engineering, and maths (STEM), in particular in experimental activities.

An initiative called STEM Scouts is an example of such informal learning activities [41]. Young individuals first study a given subject online according to a recommendation made by a teacher or mentor. They then buy an experimental kit to practice the associated practical component (build a scale model, perform a given chemical experiment) and finally demonstrate the result to the teacher or mentor, who recommends individuals for a STEM Scout badge. Individuals can then add the badge to their STEM Scouts electronic portfolio.
Tagging of informal activities executed in remote laboratories and adding them to a portfolio follows a similar process in the TRAILER project, with the exception that no teachers or mentors are involved. The main requirement is that all experiments performed in the remote laboratory must be permanently stored in an associated Internet-accessible and searchable database containing the following information:

- Who did the experiment (requires registration and login credentials): <user id >.

- Which experiment (a remote laboratory may host a number of different experiments) was carried out: <experiment id $>$.

- When the experiment was performed: <timestamp $>$.

-What were the experimental input parameters and output results: <experimental setup and results >. 


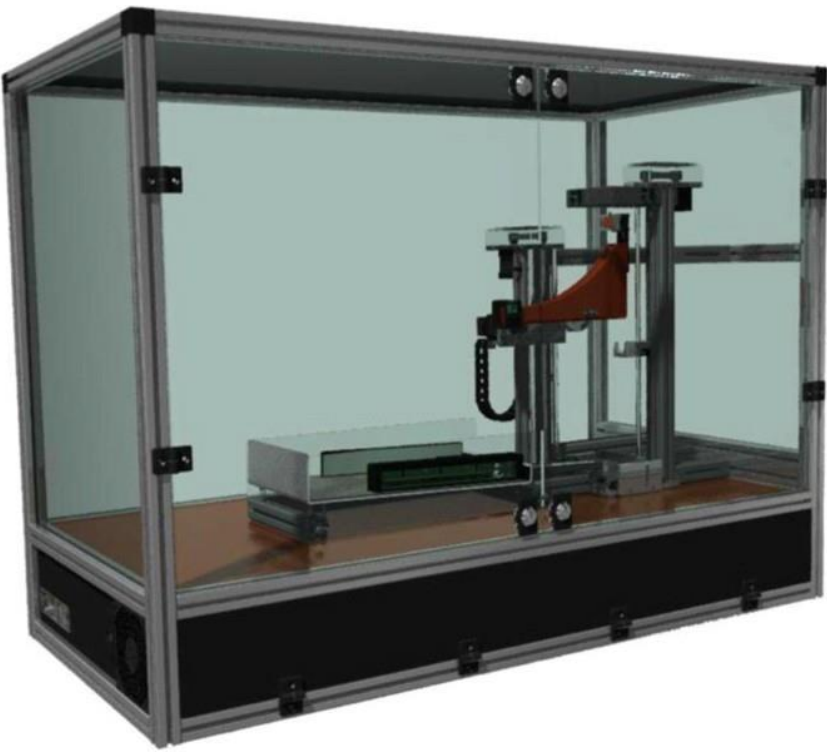

Fig. 4. Overview of the physical apparatus for remote projectile launch experiments

The remote laboratory should also contain information about the pedagogical framework associated with each supported experiment (what is the experiment about, prerequisites, learning outcomes)

Tagging of a remote experiment in TRAILER thus simply requires two (or optionally three) actions:

1. Transfer of the unique URL identifier for the pedagogical content of the remote experiment to the ILC.

2. Transfer of the unique URL identifier for the execution data for the remote experiment to the ILC.

3. (Optional) Insertion of an image illustrating the remote experiment interface to facilitate reader comprehension.

At present, there is no remote laboratory deployed in the TRAILER project that supports these two tagging actions. One remote laboratory under development is addressing these specifications by supporting a database with the identified items (who, which, when, what). This remote laboratory allows an individual to perform projectile launch experiments with a number of userconfigurable parameters for different pedagogical scenarios in which the trajectory of a falling object with a variable launch speed obeys the laws of physics. Fig. 4 provides an overview of the remote laboratory and Fig. 5 illustrates the user interface.

\subsection{Social widgets}

Social software services such as Facebook and Twitter are virtual environments in which individuals can communicate with a large audience. These social media represent a large-scale publication mechanism and have the capacity to raise social capital through strategic communications online [42]. Communications online have real effects in day-to-day life [43]. Among these effects, the increase in employment prospects has attracted much attention [44]. In recent years, professional online services to specifically harness professional profiles have become a significant element in the employment market. The strategic use of technology is increasingly important in the process of making one's way through the world.

However, the data submitted to social networks tend to be generic, personal, and available only to specific groups of individuals selected on the basis of friendship or acquaintance. While networks such as Linkedln have targeted specific social groups around professional activities, networks of friends, acquaintances, and followers tend to be somewhat of a mishmash of individuals, with communications in those networks similarly generic. However, much is revealed about individual interests, competences, and habits in these communications (including the digital habits evidenced by all participants in these media). The capacity to access and reorganise these data presents an opportunity to find new ways of harvesting social network data for new purposes including the assignment of competence to social network activities for individual or corporate purposes. This can be achieved by aggregating specific social network activity with new pieces of metadata (e.g. competence information) to contribute to different kinds of knowledge bases.

This work may be regarded in a similar vein to customer relationship management (CRM) systems, which harvest corporate intelligence from individual employee communications to pinpoint particular corporate needs [45]. These communications tend to be directly related to work purposes. The harvesting process highlights specific operational issues concerning, for example, gaps in service provision, relevant communication networks, patterns of engagement, and corporate knowledge management. However, reflexive processes in business rely on deep knowledge of individual employees and their skills and competences. CRM data reveal patterns of practice within the existing business paradigms, but not for possible new developments that would build on hitherto untapped personal competence. Therefore, to meet the need for this type of personnel knowledge management, a bridge is required so that users who have acted strategically with technology in the social software domain may make available some of these data to corporate services.

This process requires bridging between different practice domains. Technically, there are two fundamental issues regarding this connection: authentication and context. In terms of authentication, each social software service is organised on the basis of individual useraccounts. Owing partly to pressure to simplify identity management across these different services, much development effort has gone into creating architectures that make it easy to connect to different authenticated services from different contexts. The predominant technique at present is oAuth, which uses a token-passing method to authorise access to different services. In terms of context, the concept of mash-ups has increasingly meant that different web services can be accessed in ways controlled by the user through small interoperable components. This means that contexts with which users are familiar can be enhanced to include new tools or widgets, removing the need to learn new interfaces for new systems. Therefore, mash-ups in conjunction with authentication mechanisms such as oAuth mean that a variety of services can be brought together in user-defined ways to maximise effective workflows and the negotiation of different services.

For this connection, a bridge between the social software world and the world of the company is required. To achieve this, two experimental W3C widgets have been produced. Using authentication technology (oAuth), these widgets make a connection between the APIs of social software providers (Facebook and Twitter have been integrated in the first instance) and the APIs of the TRAILER corporate intelligence system (in the form of the TRAILER ILC). The basic architecture of the system is shown in Fig. 6 .

Fig. 6 shows how a user working in any context within which they can create a mash-up can embed a TRAILER widget (A) from the Wookie server. The widget first displays an user invitation to authenticate their identity for the particular social software service that applies to the widget (either Twitter or Facebook in our case). Authentication takes place through the oAuth protocol and the widget then displays the feed from the selected service. To make the bridge to TRAILER, the user is invited to further authenticate her identity for the TRAILER service (C). This gives the 


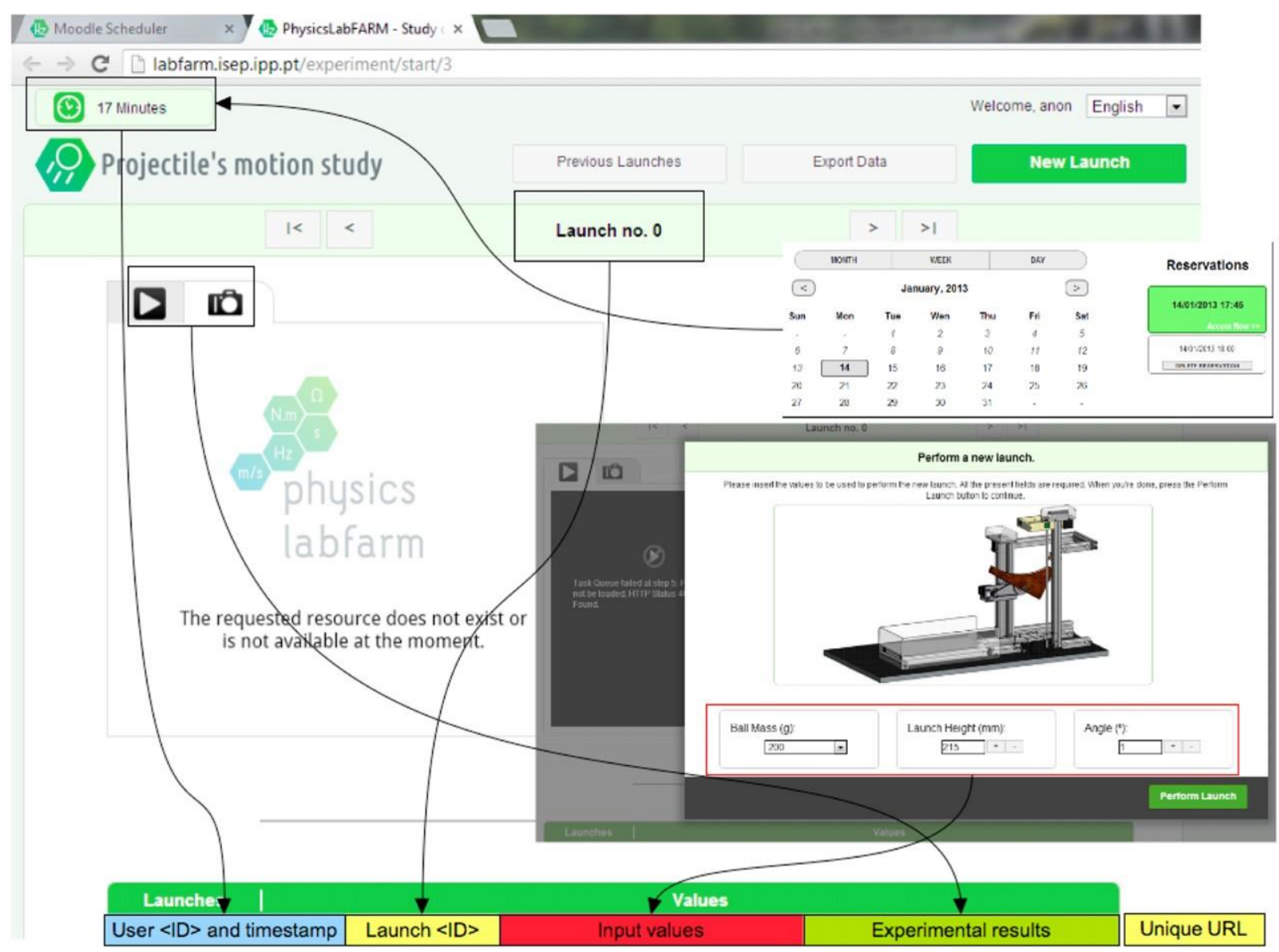

Fig. 5. User interface depicting the elements forming a database entry.

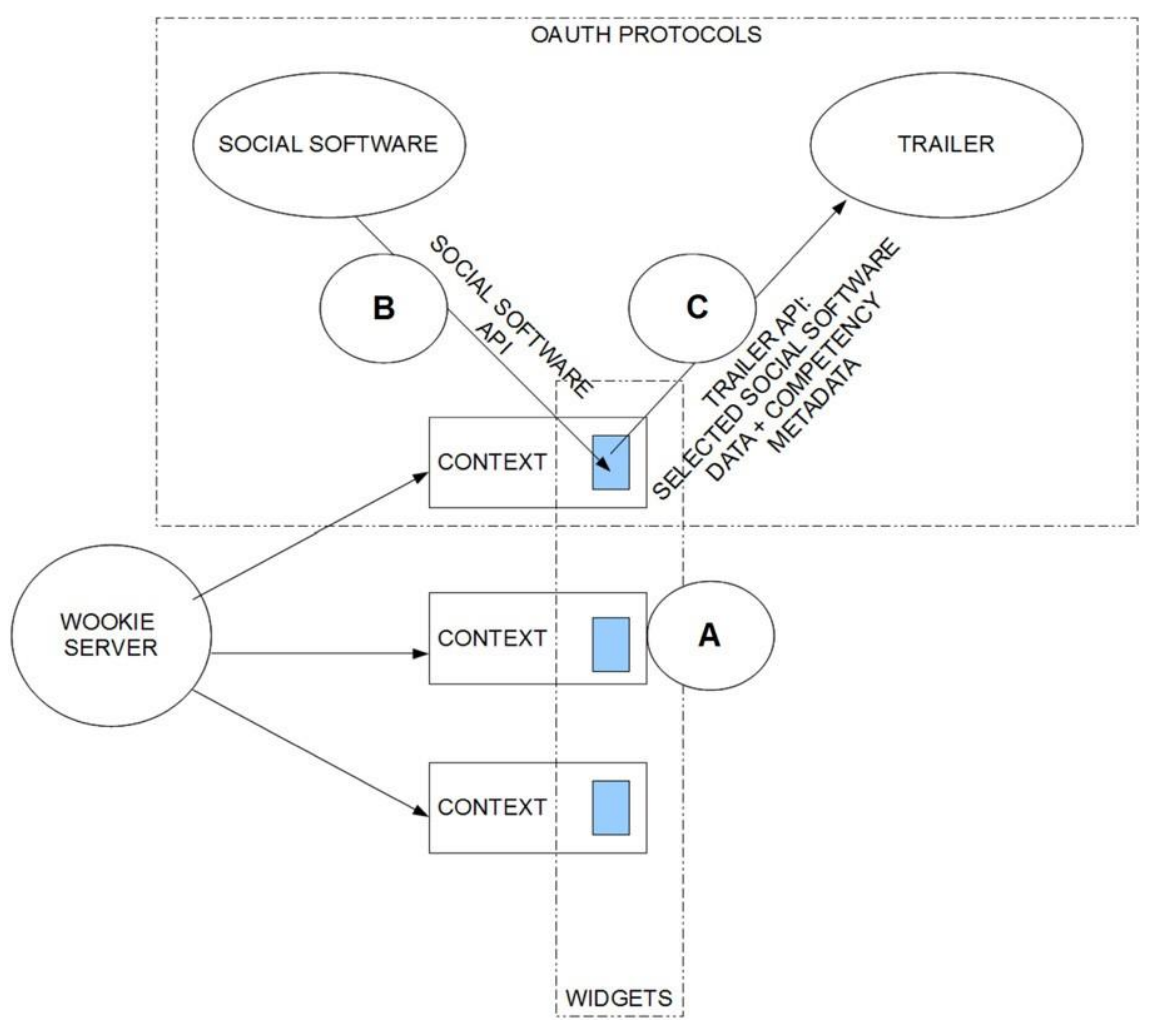

Fig. 6. Widget integration in the TRAILER architecture. 


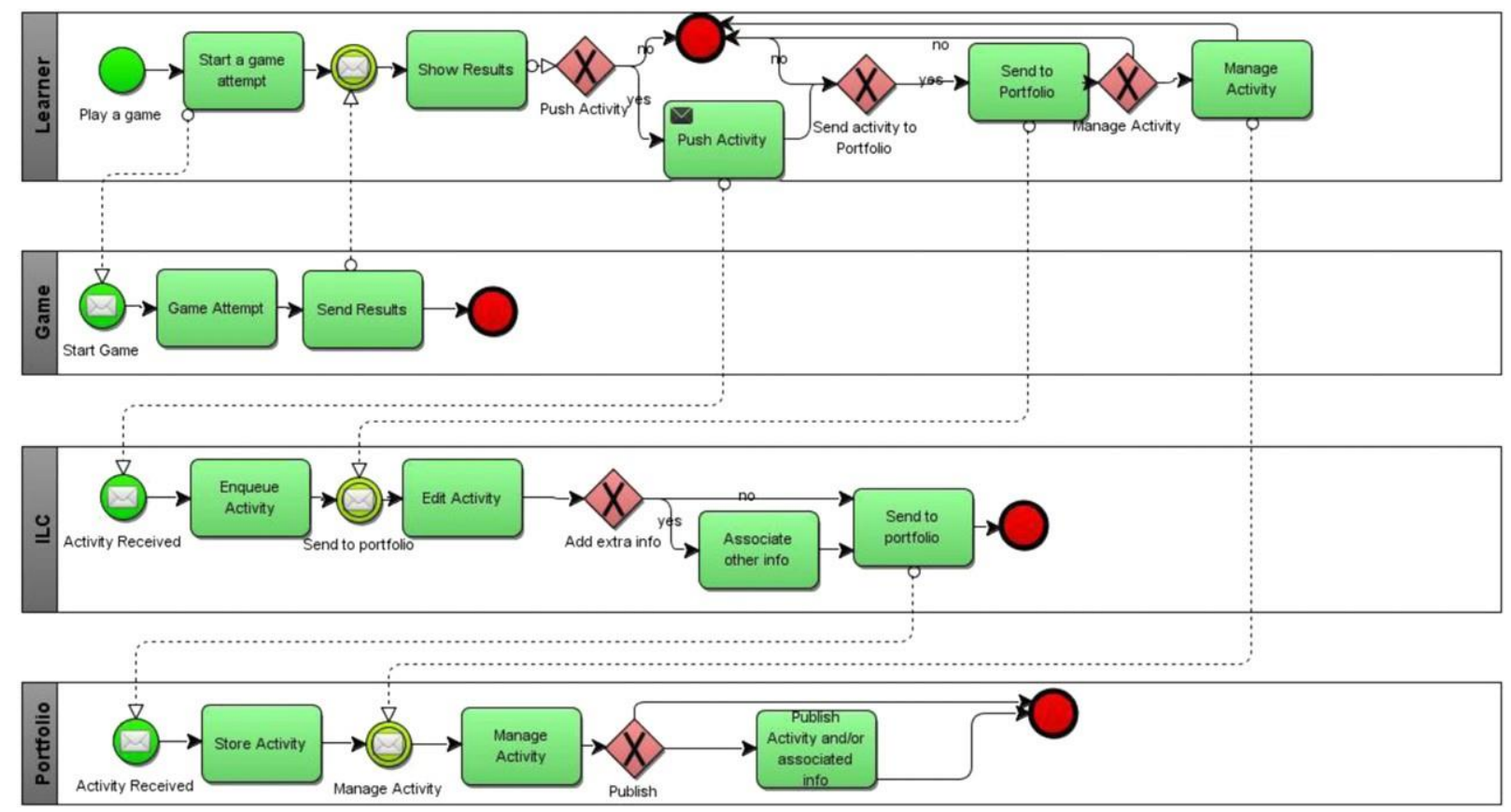

Fig. 7. Business process diagram of how an activity is carried out using a tool on the cloud and sent to the portfolio where, if the user decides so, it can be made accessible to the institution.

user options on whether to send entries from the social software service to the TRAILER store. Using the TRAILER APIs, the user can add competency metadata and keep track of which social software items have already been added to the store.

In conceiving this software approach, a number of user cases were considered:

User case 1: A worker's informal competences

In this case a worker is engaged in social network activity outside work. Social communications online may be valuable to corporate intelligence in terms of the worker's competences. Therefore, this user would be able to make a connection between her informal practice of engaging in social networks and strategic tagging and engagement with the corporate tools.

User case 2: A university student's portfolio

A learner in university is required to submit evidence for their e-portfolio. However, some of this evidence is more suited to social networks. By establishing an e-portfolio tool as a means of harvesting competence information from social network activity, the widgets act as a vehicle for bridging informal activities and relating them directly to formal learning. The process of collecting e-portfolio data becomes a process of identifying social network activity and tagging it with relevant competence information.

User case 3: A reluctant user of social software

Bridging of different types of activity and making connections between one area of life and another may present ways in which the underlying message of TRAILER - the strategic use of technology - can be delivered in a nonthreatening way to individuals who might otherwise resist engaging with social software. While the functionality and rationale behind the widgets might not result in full user engagement with the TRAILER tools, they might nevertheless prompt greater engagement with social software. The widgets help in this because, unlike other e-portfolio-type tools, they do not burden the user with new systems specialised in recording data, but instead present novel ways of looking at existing large-scale systems. This principle of coordinating services rather than creating new systems is in keeping with the basic principles of a PLE [46].

By creating a simple interface that authenticates between services and gives the user control over how data flows from one service to another, the widgets accomplish what might otherwise be achieved by creating a new system. However, consistent with the ideals of a PLE, we believe that the creation of new systems should not be preferred to finding new ways of connecting existing systems. The cognitive burden for the user is minimised because the fundamental skills for submitting data to the TRAILER store are the generic skills used for social software. Thus, a variety of different approaches can be taken for different types of user who come into contact with the TRAILER tools. This is an opportunity for social software enthusiasts to make new kinds of connections and encourages the use of social software. Thus, strategic engagement with technology for personal and corporate advantage is a realistic and achievable goal.

\section{Making decisions as a service}

The tools described above can be used independently to carry out informal learning activities. However, the TRAILER project proposes a way to make such activities visible to users' institutions or employers. One of the aims of TRAILER is to facilitate institutional decision-making by gathering information on informal learning activities carried out by users. This is achieved by collecting information on all the activities carried out using these tools and others on the cloud, and providing learners with a way of classifying and publishing the information for institutions.

All the tools previously described use ILC web service APIs to send information to the ILC. This information is selected and completed by the learner and sent to the portfolio. This tool allows the user to classify and manage their informal learning data and to publish them to the institutional environment. An example of such a workflow is shown in Fig. 7 as a business process model and notation (BPMN) diagram [47]. In this example, a user can carry out an informal activity in the game applet on the cloud. She can decide to send information on the activity to the ILC. It is then possible to add extra information (such as tags, comments, contents) to the activity and send it to the portfolio. The learner then manages the informal learning instance using the competences defined in the catalogue, adds extra information, and publishes it to the institution. 


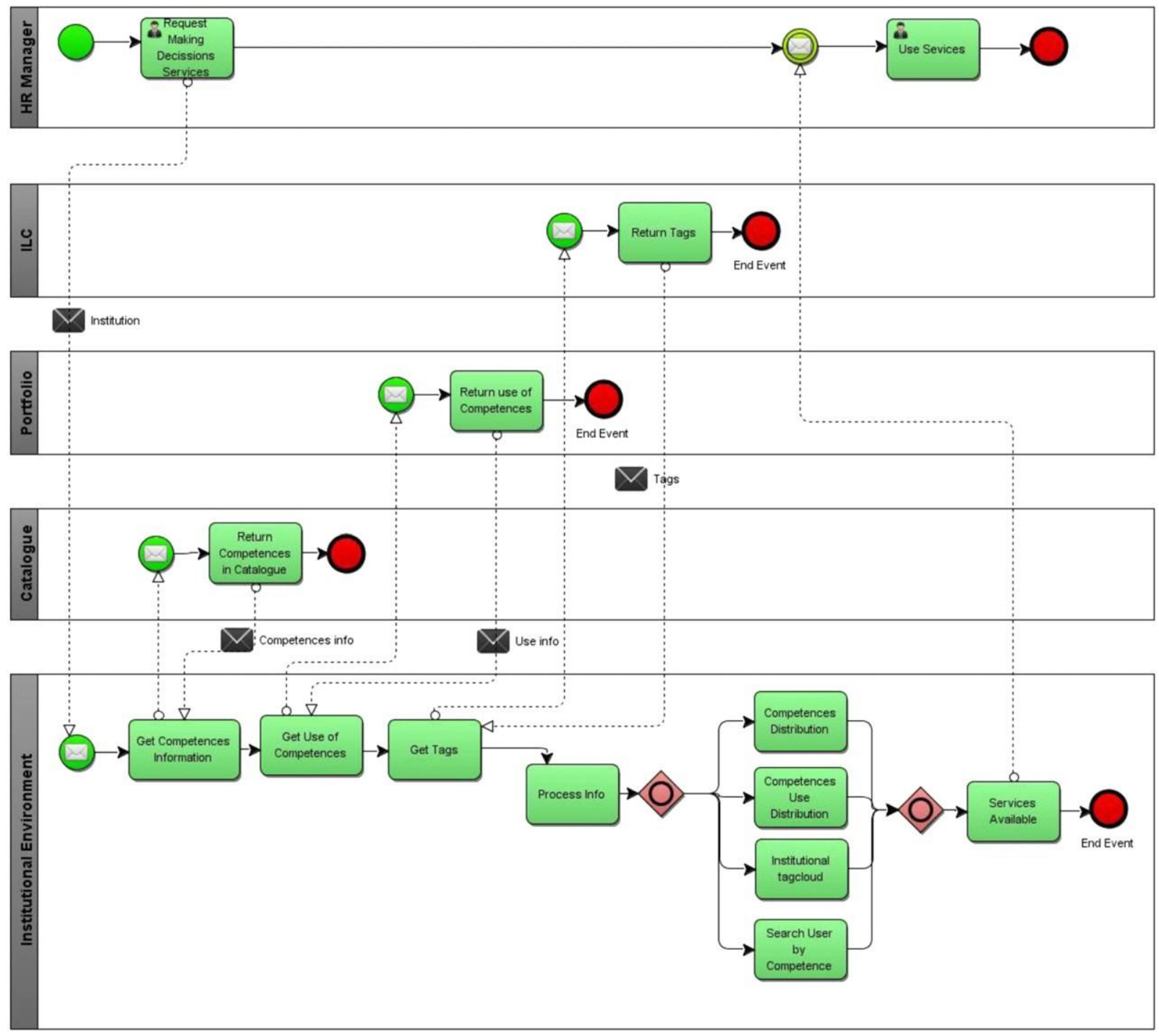

Fig. 8. BPMN diagram showing the process for making decisions on the basis of information stored and published in the system.

With the public information gathered from the cloud-based tools, the institutional environment should provide a set of services to facilitate decision-making by institutional managers. These services present information to the institution about the users, their informal learning activities, and the competences associated with those activities. Thus, web services in the system exchange information with the portfolio and the ILC to gather and present the required information. Later the institution can access dynamic reports that process this information. Specifically, the institutional system provides the following services:

- Information about the distribution of competences in the catalogue.

- Information about the distribution of public competences associated with learners' informal activities.

- Information about the distribution of public competences associated with a specificlearner.

- Information about the tags associated with the informal learning activities of persons belonging to an institution.

- A search service to locate people with a specific combination of competences in an institution.

This data-gathering process is described in the BPMN in Fig. 8 for a HR manager who requires information to make decisions within the institutional environment. The system uses different web service APIs to obtain information about the competences included in the catalogue, the informal learning activities stored and published in the portfolio, and the words used to tag the informal learning activities in the ILC. The information is processed and several services are provided so that the HR manager can make decisions related to the learning strategy of the institution or the personal development of a specific user.

In this way, informal learning carried out on the cloud by a user can be exploited by the institution.

\section{Results}

The TRAILER project is now a year old and most of the developments have been carried out as a proof of concept. The main components (competency catalogue, institutional environment, ILC, and portfolio) have been developed and integrated. Regarding the tools previously described, the game and widgets are fully implemented. All these components will be tested in two pilot actions: one oriented around users (learners/workers) and the other around institutions. Before these tests are carried out, an expert testing exercise was performed to validate the system usability. In the first instance, usability tests were conducted using individuals from the TRAILER partnership to test the TRAILER concepts and how the concepts and ideals relate to the experience of using real implemented systems. Several scenarios were posed and tested using various 
Table 1

Number of issues per Nielsen classification level for each system component.

\begin{tabular}{llllll}
\hline \multirow{2}{*}{ Component } & \multicolumn{6}{l}{ Severity } & & & \\
\cline { 2 - 6 } & Level 0 & Level 1 & Level 2 & Level 3 & Level 4 \\
\hline ILC & 1 & 6 & 7 & 1 & 1 \\
Portfolio & 5 & 7 & 14 & 3 & 1 \\
Institutional & 0 & 4 & 2 & 0 & 0 \\
environment & & & & & \\
\hline
\end{tabular}

methodologies. A cognitive walkthrough (CW) [48] was used to explore scenarios within the project and the potential experience in completing project tasks in an early system prototype. This is a useful way of highlighting potential problems in the concept or implementation of the system. The primary aim is to support the development of useable systems by identifying design deficiencies [49].

The $\mathrm{CW}$ results were complemented using the think aloud (TA) [50] technique. TA protocols involve participants talking about their experience as they are performing a set of specified tasks. Software was used to record the screen and voice.

In addition, surveys were used to gather user perceptions of the system, including a system usability scale (SUS) [51] to determine final user satisfaction and a perception of ease of use (PEOU) evaluation following the Venkatesh and Bala adaption of TAM3 [52].

Some open questions were also posed to the testers for a qualitative evaluation. The text answers were analysed and units were defined according to the component and/or thematic area involved. The outcomes were then synthesised and grouped according to unit. The results were presented in two matrices and conclusions were drawn from the information [53].

To carry out expert testing, at least two people for each partner (if possible with different degrees of familiarity with the framework) tested the system, representing a total of 14 experts. They had to complete different activities that take into account the most common actions that can be carried out using the system components. Each user performed two activities with the ILC, four with the portfolio, and three with the institutional system for the $\mathrm{CW}$ scenarios.

Among the challenges in analysing the data produced by this method, the priority was to distinguish particular types of errors and determine their severity. Patterns of recurrent breakdowns [54] in practice were identified by analysing the videos. The degree of breakdown severity was determined as the extent to which a breakdown caused disruption of flow through the CW. In effect, this led to a probability distribution for breakdowns experienced by the expert testing group.

For the CW and TA tests, 52 breakdown events were identified. The severity level was assigned according to the Nielsen classification [55]. Each component of the software architecture was tested in this way and the numbers of specific identifiable breakdown events per user is indicated in Table 1.

Although many breakdown events did not severely disrupt the flow of the task (i.e. they were level 1 or 2), the video evidence showed that the cumulative effect of these was disruptive in terms of overall user disposition to the tasks (as captured in the surveys described below). Some software issues were more serious and caused significant interruption of the task flow (i.e. at level 3 or 4). These results regarding the flow were fed back to the development team and parts of the process were redesigned.

These data were triangulated with data from the surveys. The survey data captured a more general level of satisfaction. Possibly as a result of the low-level breakdowns experienced, satisfaction levels were $18.4 \%$ less than the acceptable satisfaction level of $68 \%$ described by Sauro [56].

To validate the reliability of distinctions made in the survey analysis, Cronbach's alpha was calculated for the variance among user responses to the questionnaire questions. The alpha coefficient of 0.934 indicates a high level of consistency in user experiences across the sample of expert users. A neutral value was obtained for questions related to the PEOU evaluation.

Two matrices of results were defined for the opinions of the experts. Table 2 lists opinions related to each of the components and Table 3 classifies opinions for different themes.

The results show that although most of the experts found the ILC quite simple and straightforward, the steps should be simplified and the meaning of some fields in the form should be clarified. With regard to the portfolio, some complexities of the interface mean that it is not very intuitive in some cases. Specific areas for improvement include navigation and greater clarity for the user instructions in each section. For a complex componentbased system, there is some inefficiency in the number of clicks required to perform an action, and where possible steps should be taken to reduce this. The institutional environment was seen as quite a simple tool, but further clarity is required in describe each concept managed by the tool.

General opinions about the system were also gathered and classified according to integration, training, and improvements. The results are presented in Table 3 .

Table 3 reveals that component integration may be problematic. The final user should not perceive a change of context, so the integration and the look and feel of the system should be improved. This problem directly reflects the technical requirement for flexibility and interoperability, which can be delivered at the expense of coherence for the user experience. Regarding the necessity of special training, although the system is quite simple, a userworkshop to facilitate its use is recommended.

Taking into account these results and those for the other techniques applied, the challenge of bridging formal and informal learning activities still requires significant work for a solution that appears seamless and natural to users. However, developments to date have created the opportunity to explore these experiences in more detail and address breakdown issues experienced. Furthermore, the data reveal that breakdowns have resulted from practical problems rather than conceptual difficulties in understanding what the TRAILER tools were attempting to do. Further work will reveal whether improvements in the tools can produce a more smoothly aligned match between the TRAILER ideals and practice.

\section{Conclusions}

Wedescribed the cloud-based technologies and services used in the TRAILER project to tag, recognise, and acknowledge informal learning activities. The main aims are to allow individuals to reflect and make visible the competences and knowledge they have acquired via informal means, to build dialogue interfaces between organisations and their employees to recognise the overall hidden value of informal learning processes, and to establish methods to analyse and discover knowledge in organisations to make decisions in the short, medium, and long term.

While the integration of a complex component-based architecture overcomes many of the problems of institutionally-centric technology, this integration can present coherence problems for users. Here we argue that the benefits outweigh the disadvantages. Coherence problems can be overcome and TRAILER has demonstrated how systematic user testing can address each challenge. The potential reward is a truly learner-oriented system that also meets the needs of employers and educational institutions.

The TRAILER project takes into account informal activities carried out in different contexts, including web pages, games, social widgets, and remote laboratories. These are deployed on the cloud, which facilitates the exchange and exploitation of information. The 
Table 2

Qualitative analysis of the opinion of experts classified by component.

\begin{tabular}{|c|c|c|c|}
\hline & ILC & Portfolio & Institutional environment \\
\hline Expert 1 & - & Complex, more description, explanation needed & - \\
\hline Expert 2 & Confusing at the beginning & Complex, difficult interaction & Works well \\
\hline Expert 3 & Not intuitive, improve interaction & Simple & - \\
\hline Expert 4 & Pretty straightforward, improve interaction & Straightforward & Easy \\
\hline Expert 5 & Clear, improve interface & Intuitive & Simple and intuitive \\
\hline Expert 6 & $\mathrm{OK}$ & - & Fairly easy \\
\hline Expert 7 & Simple and straightforward & - & - \\
\hline Expert 8 & Not user friendly & - & Easy \\
\hline Expert 9 & Not easy touse & Better description and help needed & - \\
\hline Expert 10 & - & - & - \\
\hline Expert 11 & Clear and simple & Clear & Simple \\
\hline Expert 12 & Easy & Improve interaction & - \\
\hline Expert 13 & Need tosimplify & Over complex & - \\
\hline Expert 14 & Crude & Complex & More explanation to clarify concepts \\
\hline
\end{tabular}

Table 3

Qualitative analysis of the opinion of experts on the whole system classified by theme.

\begin{tabular}{|c|c|c|c|}
\hline & Integration & Training & Improvements \\
\hline Expert 1 & Is not correct & A workshop is needed & Debugging is needed to work properly, needs to be more intuitive \\
\hline Expert 2 & Issues should be solved & & Needs to be more intuitive, simplification of interaction \\
\hline Expert 3 & Integration should be solved & Teach the users & Integration in a seamless way \\
\hline Expert 4 & Does not look like an integrated product & & Task analysis and alignment with the process \\
\hline Expert 5 & Is correct & Not necessary & \\
\hline Expert 6 & Correct & Not necessary & Simplify someoptions \\
\hline Expert 7 & & Some training could be helpful & Explain concepts, improve interface \\
\hline Expert 8 & Too many changes between contexts & & Adaptation of tools to the user \\
\hline Expert 9 & - & - & Need tosimplify \\
\hline Expert 10 & Integration is not correct & Training needed & Make clearer what components do \\
\hline Expert 11 & - & - & No improvements needed \\
\hline Expert 12 & - & - & More clarity in the forms \\
\hline Expert 13 & - & Training needed & - \\
\hline Expert 14 & Integration is crude & - & Seamless integration \\
\hline
\end{tabular}

project has shown that integration and recognition of these informal learning activities is possible even if they are carried out in very heterogeneous contexts. The cloud-based framework facilitates integration of the tools used to carry out the activities and of gathering evidence and sending it to the institution. Such information makes it possible to define new services that can be used to make decisions. These services facilitate dialogue between individuals and among managers within institutions to the benefit of everyone.

\section{Acknowledgements}

This work was supported by the Lifelong Learning Program of the European Union under Project 519141-LLP-1-2011-1ES-KA3-KA3MP with support from the European Commission. This publication only reflects the views of the authors and the Commission cannot be held responsible for any use that may be made of the information contained therein. We would like to thank the other members of the partnership who participated during project development and do not appear as authors of the paper.

\section{Appendix. Measurementinstruments}

Table 4 shows the measurement instruments and the questions for each type of questionnaire and the reference on which they are based.

\section{References}

[1] F.J. García-Peñalvo, Advances in E-Learning: Experiences and Methodologies, Information Science Reference, Hershey, PA, USA, 2008.

[2] M.Á Conde, F.J. García-Peñalvo, M.J. Rodríguez-Conde, M. Alier, A GarcíaHolgado, Perceived openness of Learning Management Systems by students and teachers in education and technology courses, Computers in Human Behavior (2013) http://dx.doi.org/10.1016/j.chb.2013.05.023. in press.

[3] Y.J. Bai, S.S. Shen, L.Y. Chen, Y.S. Zhuo, Cloud learning: a new learning style, in: 2011 International Conference on Multimedia Technology, ICMT, 2011, pp. 3460-3463.
Table 4

Measurement Instruments and questions for each type of questionarie used during the pilot actions.

\begin{tabular}{|c|c|c|}
\hline & ID & Question \\
\hline \multirow{9}{*}{$\begin{array}{l}\text { SUS } \\
\text { questionnaire } \\
\text { [51] }\end{array}$} & $\begin{array}{l}\mathrm{S} 1 \\
\mathrm{~S} 2\end{array}$ & $\begin{array}{l}\text { I think that I would like to use this system frequently } \\
\text { I found the system unnecessarily complex }\end{array}$ \\
\hline & s3 & I thought the system was easy to use \\
\hline & S4 & $\begin{array}{l}\text { I think that I would need the support of a technical } \\
\text { person to be able to use this system }\end{array}$ \\
\hline & S5 & $\begin{array}{l}\text { I found that the various functions in this system were } \\
\text { well integrated }\end{array}$ \\
\hline & S6 & $\begin{array}{l}\text { I thought that there was too much inconsistency in } \\
\text { this system }\end{array}$ \\
\hline & S7 & $\begin{array}{l}\text { I imagine that most people would learn to use this } \\
\text { system veryquickly }\end{array}$ \\
\hline & S8 & I found the system very cumbersome to use \\
\hline & s9 & I felt very confident using the system \\
\hline & $\begin{array}{l}\text { S10 } \\
\text { with thi }\end{array}$ & $\begin{array}{l}\text { I needed to learn a lot of things before I could get going } \\
\text { is system }\end{array}$ \\
\hline \multirow{4}{*}{$\begin{array}{l}\text { PEOU } \\
\text { questionnaire } \\
{[52]}\end{array}$} & EOU1 & $\begin{array}{l}\text { My interaction with the system is clear and } \\
\text { understandable }\end{array}$ \\
\hline & EOU2 & $\begin{array}{l}\text { Interacting with the system does not require a lot of } \\
\text { mental effort }\end{array}$ \\
\hline & EOU3 & I find the system easy to use \\
\hline & EOU4 & I find it easy to get the system to do what I want it to do \\
\hline $\begin{array}{l}\text { Expert } \\
\text { opinion }\end{array}$ & Op1 & $\begin{array}{l}\text { What is your opinion about the system (you can also } \\
\text { describe your opinion of a specific component) }\end{array}$ \\
\hline
\end{tabular}

[4] P. Kalagiakos, P. Karampelas, Cloud Computing learning, in: 2011 5th International Conference on Application of Information and Communication Technologies, AICT, Baku, 2011, pp. 1-4.

[5] S. Downes, E-learning 2.0, Elearn Magazine 2005 (2005) 1.

[6] J. Mott, D. Wiley, Open for learning: the CMS and the open learning network, In Education 15 (2009) 3-22.

[7] G. Attwell, e-Portfolios-the DNA of the personal learning environment? Journal of e-Learning and Knowledge Society 3 (2007) 39-61.

[8] V.B. Weigel, Deep Learning for a Digital Age: Technology's Untapped Potential to Enrich Higher Education, Jossey-Bass, 2001. 
[9] P. Mell, T. Grance, The NIST Definition of Cloud Computing, National Institute of Standards and Technology, Gaithersburg, 2011.

[10] R. Buyya, C.S. Yeo, S. Venugopal, J. Broberg, I. Brandic, Cloud computing and emerging IT platforms: vision, hype, and reality for delivering computing as the 5th utility, Future Generation Computer Systems 25 (2009) 599-616.

[11] B. Hirsch, J.W.P. Ng, Education beyond the cloud: anytime-anywhere learning in a smart campus environment, in: 2011 International Conference for Internet Technology and Secured Transactions, ICITST, Abu Dhabi, 2011 pp. 718-723.

[12] M.J. Wang, An intelligent learning model based on cloud computing, EBTIC's International iCampus Initiative Internal Report, 2011, pp. 1-16.

[13] W. Clark, K. Logan, R. Luckin, A. Mee, M. Oliver, Beyond Web 2.0: mapping the technology landscapes of young learners, Journal of Computer Assisted Learning 25 (2009) 56-69.

[14] G. Attwell, The personal learning environments-the future of eLearning? eLearning Papers 2 (2007) 1-8.

[15] J. Adell, L. Castañeda, Los Entornos Personales de Aprendizaje (PLEs): una nueva manera de entender el aprendizaje, in: R. Roig Vila, M. Fiorucci (Eds.), Claves para la investigación en innovación y calidad educativas. La integración de las Tecnologías de la Información y la Comunicación y la Interculturalidad en las aulas. Stumenti di ricerca per l'innovaziones e la qualità in ámbito educativo. La Tecnologie dell'informazione e della Comunicaziones e l'interculturalità nella scuola, Marfil-Roma TRE Universita degli studi, Alcoy, Spain, 2010.

[16] S. Halliday-Wynes, F. Beddie, Informal Learning at a Glance, National Centre for Vocational Education Research, Adelaide, Australia, 2009

[17] M. Dale, J. Bell, Informal learning in the workplace, Department for Education and Employment, 1999.

[18] F.J. García-Peñalvo, R. Colomo-Palacios, M.D. Lytras, Informal learning in work environments: training with the social web in the workplace, Behaviour \& Information Technology 31 (2012) 753-755.

[19] F.J. García-Peñalvo, M.Á. Conde, V. Zangrando, A. García-Holgado, A.M. Seoane, M.A. Forment, N. Galanis, J. Janssen, F. Brouns, H. Vogten, D. Griffiths, A Mykowska, G.R. Alves, M. Minović, TRAILER project (tagging, recognition, acknowledgment of informal learning experiences). A methodology to make visible learners' informal learning activities to the institutions, Journal of Universal Computer Science (2013) in press.

[20] F.J. García-Peñalvo, V. Zangrando, A. García Holgado, M.Á. Gónzalez Conde, A.M. Seone Pardo, M. Alier Forment, J. Janssen, D. Griffiths, A. Mykowska G. Ribeiro Alves, M. Minovic, TRAILER project overview: tagging, recognition and acknowledgment of informal learning experiences, in: F.J. García-Peñalvo, L. Vicent, M. Ribó, A. Climent, J.L. Sierra, A. Sarasa (Eds.), 2012 International Symposium on Computers in Education (SIIE), Institute of Electrical and Electronics Engineers, 2012. IEEE Catalog Number CFP1286T-ART, Andorra la Vella.

[21] Z.Z. Yu, The basic principles of cloud computing and its impact on education, in: Satellite TV and Broadband Multimedia, 2010, pp. 67-70.

[22] N. Fernando, S.W. Loke, W. Rahayu, Mobile cloud computing: a survey, Future Generation Computer Systems 29 (2013) 84-106.

[23] X.M. Wang, X.Q. Jia, Cloud computing on the impact of higher education, Science \& Technology Information (2010) 397-398.

[24] S. Ouf, M. Nasr, Y. Helmy, An enhanced e-learning ecosystem based on an integration between cloud computing and Web2.0, in: 2010 IEEE International Symposium on Signal Processing and Information Technology, ISSPIT, 2010, pp. 48-55.

[25] M. Al-Zoube, E-Learning on the cloud, International Arab Journal of eTechnology 1 (2009) 58-64.

[26] F.J. García-Peñalvo, M.Á. Conde, M. Johnson, M. Alier, Knowledge co-creation process based on informal learning competences tagging and recognition, International Journal of Human Capital and Information Technology Professionals 4 (2013) in press.

[27] M. Prensky, Digital Game-Based Learning, Paragon House, 2007.

[28] P. Moreno-Ger, D. Burgos, I. Martínez-Ortiz, J.L. Sierra, B. Fernández Educational game design for online education, Computers in Human Behavior 24 (2008) 2530-2540.

[29] D. Wong, B. Packard, M. Girod, K. Pugh, The opposite of control: a Deweyan perspective on intrinsic motivation in "After 3" technology programs, Computers in Human Behavior 16 (2000) 313-338.

[30] M.D. Aguilera, A. Mendiz, Video games and education: education in the face of a "parallel school", Computers in Entertainment 1 (2003) 1-10.

[31] J.A. Estalló, Los videojuegos. Juicios y prejuicios, Planeta, Barcelona, 1994.

[32] M.J. Koepp, R.N. Gunn, A.D. Lawrence, V.J. Cunningham, A. Dagher, T. Jones, D.J. Brooks, C.J. Bench, P.M. Grasby, Evidence for striatal dopamine release during a video game, Nature 393 (1998) 266-268.

[33] M. Minovic, V. Stavljanin, M. Milovanovic, D. Starcevic, Adventure Game Learning Platform, IGIGlobal, 2010, pp. 12-21.

[34] B. Aktan, C.A. Bohus, L.A. Crowl, M.H. Shor, Distance learning applied to control engineering laboratories, IEEE Transactions on Education 39 (1996) 320-326.

[35] A.K.M. Azad, M.E. Auer, V.J. Harward, Internet Accessible Remote Laboratories: Scalable E-Learning Tools for Engineering and Science Disciplines, IGI Global, 2011.

[36] M.P. Kazmierkowski, M. Liserre, Advances on remote laboratories and elearning experiences, in: L. Gomes, J. Garcia-Zubia (Eds.), Book News, Industria Electronics Magazine, IEEE 2 (2008), 45-46.

[37] E.D. Lindsay, M.C. Good, Effects of laboratory access modes upon learning outcomes, IEEE Transactions on Education 48 (2005) 619-631.
[38] J. Ma, J.V. Nickerson, Hands-on, simulated, and remote laboratories: a comparative literature review, ACM Computing Surveys 38 (2006) 7

[39] J.G. Zubía, G.R. Alves, Using Remote Labs in Education: Two Little Ducks in Remote Experimentation, Universidad de Deusto, 2012.

[40] L.D. Feisel, A.J. Rosa, The role of the laboratory in undergraduate engineering education, Journal of Engineering Education (2005) 121-130.

[41] S. Scouts, Available at: http://stemscouts.org/ (accessed 12.06.13)

[42] M. Johnson, D. Sherlock, Learner reflexivity, technology and "making our way through the world", International Journal of Continuing Engineering Education and Life-Long Learning 19 (2009) 352-365.

[43] I. Guy, N. Zwerdling, D. Carmel, I. Ronen, E. Uziel, S. Yogev, S. OfekKoifman, Personalized recommendation of social software items based on social relations, in: Proceedings of the 3rd ACM Conference on Recommender Systems, ACM, New York, 2009, pp. 53-60.

[44] M.M. Skeels, J. Grudin, When social networks cross boundaries: a case study of workplace use of Facebook and Linkedln, in: Proceedings of the ACM 2009 International Conference on Supporting Group Work, ACM, Sanibel Island, Florida, USA, 2009, pp. 95-104.

[45] F. Buttle, Customer Relationship Management, Taylor \& Francis, 2012.

[46] M. Johnson, O. Liber, The personal learning environment and the human condition: from theory to teaching practice, Interactive Learning Environments 16 (2008)3-15

[47] OMG, Business process model and notation, version 2.0, 2011

[48] P.G. Polson, C. Lewis, J. Rieman, C. Wharton, Cognitive walkthroughs: a method for theory-based evaluation of user interfaces, International Journal of Man-Machine Studies 36 (1992) 741-773.

[49] T. Boren, J. Ramey, Thinking aloud: reconciling theory and practice, IEEE Transactions on Professional Communication 43 (2000) 261-278.

[50] C.H. Lewis, Using the "Thinking Aloud" method in cognitive interface design, 1982.

[51] J. Brooke, SUS: a quick and dirty usability scale, in: P.W. Jordan, B. Thomas, B.A. Weerdmeester, I.L. McClelland (Eds.), Usability Evaluation in Industry, Taylor \& Francis, 1996.

[52] V. Venkatesh, H. Bala, Technology acceptance model 3 and a research agenda on interventions, Decision Sciences 39 (2008) 273-315.

[53] M.B. Miles, A.M. Huberman, Qualitative Data Analysis: An Expanded Sourcebook, Sage Publications, 1994

[54] T. Winograd, F. Flores, Understanding Computers and Cognition: A New Foundation for Design, Ablex Publishing Corporation, 1986.

[55] J. Nielsen, Usability Engineering, Academic Press, Boston, 1994.

[56] J. Sauro, A Practical Guide to the System Usability Scale: Background, Benchmarks \& Best Practices, CreateSpace, 2011. 
